\title{
ROTATIVIDADE NAS EMPRESAS: MOTIVOS INTERNOS E EXTERNOS
}

\author{
Letícia Pavanello ${ }^{1}$, Eliana V. Jaeger ${ }^{2}$ \\ ${ }^{1}$ Universidade do Estado de Santa Catarina - UDESC \\ ${ }^{2}$ Centro de Educação Superior do Alto Vale do Itajaí - CEAVI \\ leticiapavanello13@gmail.com, eliana@ibnet.com.br
}

\begin{abstract}
Resumo: Atualmente, é evidente que o crescimento e o desenvolvimento de novas empresas no ramo têxtil estão diretamente ligados ao crescimento do assunto rotatividade, ou seja, a quantidade de entradas e saídas de colaboradores. Quando esse número é expressivo, pode prejudicar o crescimento e progresso da organização. Por ser um setor que depende de um número significativo de empregados, necessita apresentar características que atraiam novas pessoas ou até mesmo incentive seus próprios colaboradores para permanecerem na empresa por longo tempo. Devido à competitividade entre as empresas e à necessidade de manter um quadro de colaboradores estáveis e satisfeitos dentro da empresa, nasce a importância de identificar se os motivos que provocam a rotatividade são causados por fatores internos ou externos, para que a empresa tenha consciência desses problemas, a fim de minimizá-los ou até eliminá-los. O objetivo deste artigo é identificar e demonstrar quais os principais motivos propagadores da turnover. Os resultados iniciais mostram que um dos principais motivos elencados é a satisfação no trabalho e a qualidade de vida proporcionada no ambiente de trabalho, dessa forma, podemos observar que a questão da remuneração não é o fator primordial.
\end{abstract}

Palavras-chave: Rotatividade. Fatores Internos. Fatores Externos.

Abstract: Currently, it is evident that the growth and development of new companies in the textile business is directly linked to the growth of the turnover issue, in other words, the amount of inputs and outputs of the same employees, that when this number is significant can impair growth and progress the organization. For being a sector that depends on a significant number of employees, need to present features that attract new people or even encourage their own employees to remain in the business for a long time. Due to competition between companies and the necessity to maintain a framework of stable and satisfied employees within the company, rises the importance of identifying whether the reasons that cause turnover are caused by internal or external factors, for the company to be aware of them in order to minimize them or even eliminate them. The purpose of this paper is to identify and to demonstrate the main reasons for turnover propagators. The initial results show that one of the main reasons is a job satisfaction and the quality of life offered in the workplace, thus we can observe that the issue of remuneration is not the primary factor.

\section{1 - Introdução}

Atualmente, é visível a intensidade de como as coisas estão se transformando, diversos são os fatores que contribuem para isso. Uma das áreas empresariais que sofre constantemente com mudanças é a de recursos humanos, pois tem contato com um dos principais patrimônios 
de uma empresa, ou seja, as pessoas. Segundo Chiavenato (2004), as pessoas passam a ser o diferencial competitivo em uma organização, pois é através dela que se mantém e se promove o sucesso. Ou seja, é nas pessoas que se encontra o potencial para o desenvolvimento e evolução da empresa.

Destaca-se que ter os colaboradores como parceiros dentro da organização tornou-se uma vantagem muito competitiva para a empresa. A administração de recursos humanos passa a ter um papel mais amplo e significativo, visto que não somente faz a parte burocrática, mas sim, possui uma ligação de companheirismo, transparência e partilha suas metas e objetivos com os empregados. Assim, o artigo descreve a importância de manter os empregados motivados dentro da organização, além de identificar os motivos internos e externos que provocam a rotatividade, mediante uma pesquisa bibliográfica.

\section{2- A rotatividade interna e externa}

A rotatividade dos recursos humanos, segundo Chiavenato (1998), é a movimentação de pessoas entre uma organização e seu ambiente, sendo que essas movimentações são caracterizadas e definidas pelo volume de pessoas que ingressam e saem da organização. A crescente rotatividade nas empresas, também conhecida como turnover, está relacionada entre admissões e demissões, ou a substituição de trabalhadores antigos por novos (SANTOS 2010).

É fundamental que cresça, a cada dia, a consciência nas organizações de que a rotatividade pode ser considerada um problema grave que afeta tanto as finanças, com os custos originados pela saída de um empregado, diversos são os motivos que elevam a rotatividade nas empresas. Segundo Milkovich; Boudreau (2008), citado por Santos (2010), a decisão de o funcionário pedir demissão é influenciada por diversos fatores, alguns são dificilmente controláveis pela organização, como o índice de desemprego, responsabilidade familiar e interesse por outras empresas.

Para Shigunov; Assumpção (1998), a preocupação está voltada para a qualidade de vida no ambiente de trabalho, a sua segurança e a oportunidade de crescimento pessoal e profissional de seus empregados. Já para Ferreira e Siqueira (2005), o principal fator que influencia na rotatividade é a satisfação no trabalho, ou seja, as empresas precisam desenvolver ações de comprometimento entre empregado e organização, desenvolver novos planos que beneficiem seus funcionários, identificar suas insatisfações e minimizá-las, desenvolver métodos que aumentem a satisfação e diminuam a rotatividade.

Oferecer qualidade de vida em benefício de seus colaboradores, em forma de planos de saúde, assistência médica, ajuda na redução da rotatividade, visto que demonstra a preocupação com a saúde e bem-estar de seus funcionários, os quais, na verdade, são a base de tudo, isso significa que se eles estão bem fisicamente, proporcionam maior produtividade, qualidade da execução do serviço, empenho e dedicação (SCALCO, 2008).

A satisfação e a qualidade de vida no trabalho são indiscutivelmente fatores primordiais no assunto rotatividade, pois, para Vieira (2011), a satisfação é um estado emocional, tida como um sentimento, resultado das condições do trabalho, ou seja, varia de acordo com as políticas adotadas dentro da organização, as quais podem influenciar positivamente quanto negativamente. Profissionais satisfeitos além de se comprometerem 
mais com os projetos da empresa, reduzem o índice de rotatividade, já em um ambiente em que a satisfação é baixa, a produtividade é reduzida e a taxa de rotatividade é elevada.

Para Ferreira e Siqueira (2005), a partir do momento em que uma pessoa passa a fazer parte da empresa, ela juntamente assume a responsabilidade de seguir e respeitar as normas, os valores e a sua cultura, além de estar disposta a trabalhar em função do desenvolvimento e do crescimento da organização. Por outro lado, essa pessoa espera uma retribuição justa pelo trabalho prestado e, a partir disso, cria-se uma relação de troca, em que a empresa oferece salário e benefícios a fim de atrair, incentivar e motivar seus empregados, e por parte dos empregados, a fim de obter os recursos necessários para satisfazer as suas necessidades.

Segundo Souza (2003), muitos gestores pensam que o principal fator está no salário, no entanto, o profissional busca reconhecimento tanto pessoal quanto profissional, e isso vale muito mais que dinheiro e, com certeza, são fatores essenciais para a redução da rotatividade. Segundo Carmo (2007), com a implantação de novas políticas de recursos humanos que visam à melhoria do desenvolvimento da organização, precisa estar associada aos interesses dos colaboradores, visto que o principal talento de uma empresa está nas pessoas. O estudo de Shigunov e Assumpção (1998) aponta que a inexistência de uma política adequada de recursos humanos, falta de planejamento eficaz para seus empregados e a falta de oportunidade de crescimento na organização, além do baixo salário, são os principais fatores que contribuem para o aumento da rotatividade. Oliveira (2006) afirma que a implementação de políticas estratégicas para satisfazer e poder avaliar as necessidades atuais e futuras de seus empregados, oferecer oportunidades de crescimento, contribui para o sucesso da organização.

\section{3 - Metodologia, discussão e análise dos dados}

Foram coletados cerca de vinte textos de autores e anos diferentes, retidos do site do Capes para o desenvolvimento deste artigo, no dia 30 de maio de 2014. No presente artigo, foram destacados oito principais autores, os quais elencaram os principais motivos que provocam a rotatividade, sendo que, os pesquisadores identificavam mais de um motivo, por conta disso, o gráfico não está em conformidade com a quantidade de autores destacados. $\mathrm{O}$ gráfico foi elaborado a partir do conceito da revisão sistemática e, assim, a aplicação do método quantitativo, porque conforme Castro (2001), a principal decisão na elaboração da revisão sistemática é a determinação do foco.

\section{Gráfico: Motivos que provocam a Rotatividade}

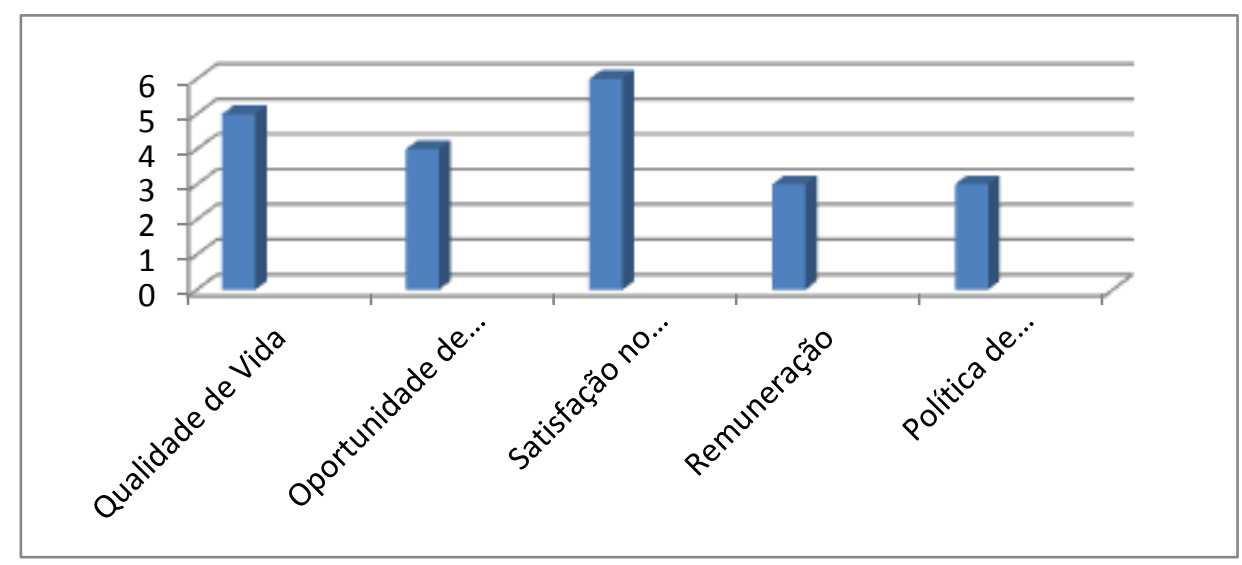

Fonte: Do autor. 
Segundo o levantamento dos dados, os principais motivos elencados são a satisfação no trabalho e a qualidade de vida proporcionada no ambiente de trabalho, dessa forma, podemos observar que a questão da remuneração não é o fator primordial em relação à causa da rotatividade, e sim, a motivação dentro da empresa. A oportunidade de crescimento na organização também é outro fator em destaque, ou seja, os colaboradores precisam enxergar possibilidades de crescer, progredir e se desenvolver no seu trabalho, assim, irão sentir-se motivados e esforçados para ajudar a empresa a alcançar suas metas. Isso será bom tanto para o empregado quanto para a própria empresa.

A política de recursos humanos é outro ponto elencado entre os autores, demonstrando que os gestores precisam desenvolver políticas que compreendam os anseios e as necessidades de seus empregados para proporcionar o maior conforto e bem-estar possível para que se sintam bem, trabalhando na empresa e não sintam vontade de se desligar do quadro da empresa.

\section{4 - Considerações finais}

Diante da pesquisa realizada no site da Capes em relação aos diversos autores que estudaram e evidenciaram os principais motivos propagadores da rotatividade, podemos identificar que muitos deles são causados dentro da própria organização e, dessa forma, os próprios gestores podem adotar políticas que promovam o bem-estar de seus colaboradores, proporcionando melhor qualidade de vida, motivando seus empregados, valorizando o trabalho e tendo em mente que a organização não seria nada sem ele, não seria nada, se não houvesse pessoas comprometidas com o desenvolvimento da empresa. Neste contexto, a remuneração é um ponto importante a ser considerado pelo colaborador, porém, na maioria das vezes, não é o principal, sendo cada vez mais valorizados outros fatores antes do salário, tais como possibilidade de crescimento profissional, benefícios, motivação e outros.

\section{Referências}

CARMO, M. R. A Importância do talento humano como recurso estratégico. 2007. Dissertação (Pós-Graduação) - Universidade Católica de Brasília. 2007.

CHIAVENATO, I. Gestão de pessoas: e o novo papel dos recursos humanos nas organizações. Rio de Janeiro: Elsevier, 2004 - $9^{\text {a }}$ Reimpressão.

FERREIRA, M. L. C. Bisi; SIQUEIRA, M. M. M. Antecedentes de intenção da rotatividade: estudo de um modelo psicossocial. 2005. Dissertação (Mestrado) Universidade Metodista de São Paulo, SP, 2005.

OLIVEIRA, J. P.; OLIVEIRA de B. Psicologia dos Recursos Humanos, do Trabalho e das Organizações. 2009. Tese de (Mestrado) - Psicologia Universidade de Lisboa, Faculdade de Psicologia e de Ciências da

SCALCO, V. S. Modelo para avaliação da eficácia da gestão de recursos humanos em saúde. Mestrado - Universidade Federal de Santa Catarina. Florianópolis. 2008 
SHIGUNOV, N. A., ASSUMPÇÃO, P. G. O processo de rotação de pessoal da Universidade Estadual de Maringá (UEM): Causas e Consequências. Ano 1998.

SANTOS, Hugo. 2010. Como lidar com a rotatividade de pessoal. Disponível em: <http://www.administradores.com.br/artigos/economia-e-financas/como-lidar-com-arotatividade-de-pessoal/50229/> Acesso em: 17 agosto de 2014.

SOUZA, K. R. R. S. A rotatividade e as condições de trabalho dos profissionais de enfermagem: Um enfoque da ergonomia. 2003. Dissertação (Mestrado) - Universidade Federal de Santa Catarina, SC, 2003.

VIEIRA, R. F. M. N. Satisfação e Qualidade de vida factores preditores da rotatividade dos comerciais do grupo MCoutinho. 2011. Dissertação - Universidade Católica Portuguesa. Braga, 2011. 